\title{
A taste of the new ReCiPe for life cycle assessment: consequences of the updated impact assessment method on food product LCAs
}

\author{
Erik Dekker ${ }^{1,2} \cdot$ Michiel C. Zijp ${ }^{2} \cdot$ Mirjam E. van de Kamp ${ }^{2}$ Elisabeth H. M. Temme ${ }^{2} \cdot$ Rosalie van Zelm ${ }^{1}$
}

Received: 29 October 2018 / Accepted: 16 June 2019 / Published online: 9 July 2019

(C) The Author(s) 2019

\begin{abstract}
Purpose Recently, an update of the Life Cycle Impact Assessment (LCIA) method ReCiPe was released: ReCiPe 2016. The aim of this study was to analyse the effect of using this update instead of the previous version: ReCiPe 2008. Do the absolute outcomes change significantly and if so, does this lead to different conclusions and result-based recommendations?

Methods Life cycle assessments (LCAs) were conducted for 152 foods for which cradle-to-plate inventories were available and that together are estimated to account for $80 \%$ of the total greenhouse gas emissions, land use and fossil resource depletion of food consumption in the Netherlands. The LCIA was performed on midpoint and endpoint level, with both ReCiPe 2008 and 2016, and using the three perspectives provided by ReCiPe. Both the uses of the global-average characterisation factors (CFs) and the Dutchspecific CFs were explored.

Results and discussion Results showed a strong correlation between LCAs performed with ReCiPe 2008 and with 2016 on midpoint and endpoint level, with Spearman's rank correlation between 0.85 and 0.99 . Ranking of foods related to their overall environmental impact did not differ significantly between methods when using the default hierarchist perspective. Differences on endpoint level were largest when using the individualist perspective. The predicted average absolute impact of the foods studied did change significantly when using the new ReCiPe, regardless of which perspective was used: a larger impact was found for climate change, freshwater eutrophication and water consumption and a lower impact for acidification and land use. The use of Dutch CFs in ReCiPe 2016 leads to significant differences in LCA results compared with the use of the global-average CFs. When looking at the average Dutch diet, ReCiPe 2016 predicted a larger impact from greenhouse gas emissions and freshwater eutrophication, and a lower impact from acidification and land use than ReCiPe 2008.

Conclusions The update of ReCiPe leads to other LCIA results but to comparable conclusions on hotspots and ranking of food product consumption in the Netherlands. Looking at the changes per product due to the update, we recommend updating endpoint-level LCAs conducted with ReCiPe 2008, especially for products that emit large amounts of $\mathrm{PM}_{2.5}$ or consume large amounts of water within their life cycle. As new and updated methods reflect the scientific state of art better and therefore include less model uncertainty, we recommend to always use the most recent and up-to-date methodology in new LCAs.
\end{abstract}

Keywords Dutch food consumption · Cradle-to-grave $\cdot$ Characterisation · Midpoint · Endpoint $\cdot$ Regionalisation $\cdot$ Life cycle impact assessment

Responsible editor: Serenella Sala

Electronic supplementary material The online version of this article (https://doi.org/10.1007/s11367-019-01653-3) contains supplementary material, which is available to authorized users.

Rosalie van Zelm

r.vanzelm@science.ru.nl

1 Department of Environmental Science, Institute for Water and Wetland Research, Faculty of Science, Radboud University, Nijmegen, The Netherlands

2 National Institute for Public Health and the Environment, Bilthoven, The Netherlands

\section{Introduction}

To perform Life Cycle Assessment (LCA) studies, there is a variety of Life Cycle Impact Assessment (LCIA) methods available. The International Standard for LCA (ISO 1404014044) does not specify which LCIA method should be used, which means the choice for LCIA method differs per study (Finkbeiner et al. 2006; Hauschild et al. 2013). Various LCA studies compared different LCIA methods (Cavalett et al. 2013; Koiwanit et al. 2014; Bueno et al. 2016). They often concluded that, though methods can be relatively in 
agreement, the results depend on the method that is chosen and so are the conclusions. The variation in results is caused by intrinsic differences in the characterisation models, which result in different characterisation factors $(\mathrm{CFs})$ for the same substance or even different contributing substances for the same impact category. Variations in characterisation models are due to the inclusion of various processes, in different regional and temporal scales, but also due to variations in research areas of the institutions where assessment methods are developed. Bueno et al. (2016) conclude that the most appropriate LCIA methodology would always be the latest version. Updates of methods could, however, change conclusions obtained in LCA case studies.

To further progress LCIA methods beyond the current state-of-art, the widely used (see e.g. Manfredi and Vignali 2014; Smetana et al. 2015; Goldstein et al. 2016) ReCiPe 2008 method (Goedkoop et al. 2009) was updated to its version of 2016 (Huijbregts et al. 2016). The ReCiPe provides a harmonised implementation of cause-effect pathways for the calculation of both midpoint and endpoint characterisation factors. To make a step forward in overcoming shortcomings, the ReCiPe update focused on (1) providing CFs that are representative for the global scale, while maintaining the possibility for a number of impact categories to implement CFs at a country scale and (2) improving the characterisation models to determine mid-to-endpoint factors.

The goal of this study was to systematically compare absolute and relative LCA results based on ReCiPe 2008 and ReCiPe 2016 and to discuss the implications for the interpretation of the LCA results by analysing if the relative ranking of the foods changes significantly when switching from $\mathrm{ReCiPe}$ 2008 to ReCiPe 2016. For this, a case study using data for selected foods that are commonly consumed in the Netherlands was used. The comparison is made on midpoint level using both global-average CFs and Dutch-specific CFs and on endpoint level using global-average $\mathrm{CFs}$. Furthermore, the analysis is performed at the level of individual food per kilogramme and at the level of an average Dutch consumption pattern. Subsequently, the implications of using the updated methodology for practitioners and stakeholders are discussed.

\section{Methods}

\subsection{Goal and scope}

For the comparison of LCA results using ReCiPe 2008 and ReCiPe 2016, attributional LCAs were performed for 152 foods consumed in the Netherlands. These foods are estimated to account for approximately $80 \%$ of food-related greenhouse gas emissions, land use and fossil resource depletion (De Valk et al. 2016). One kilogramme of food prepared at plate was used as a functional unit.

\section{$2.2 \mathrm{LCl}$}

The Life Cycle Inventory (LCI) consisted of 152 different foods available in the Netherlands (De Valk et al. 2016). Data were obtained from ecoinvent v3.1 (Weidema et al. 2013), Agri-footprint v2.0 (Blonk Agri-footprint BV. Blonk Agri-footprint 2015), ELCD v3.1, EU \& DK Input Output Database, Broekema et al. (2015a), Broekema et al. (2015b), Kuling et al. (2015), Kuling and Scholten (2015) and Broekema et al. (2016). The LCI data were composed to assess climate change, terrestrial acidification, freshwater eutrophication, marine eutrophication, water consumption and land use. In accordance with PAS2050-1, emissions were allocated based on economic value, except for dairy products where bio-physical allocation was used (BSI 2012; JRC 2015). Average emission values over the year were taken, neglecting seasonal variability. Crop rotation and change in surface albedo were outside the scope of the study. It was assumed that there were no quality differences between products or any differences between brands of the same product. The analysis included all extractions and emissions from cradle to plate, life cycle stages of human waste were not included. Data on pesticide use were absent from the LCI.

For the result analyses, foods were classified into nine different categories based on the GloboDiet classification categories (Table S1, Electronic Supplementary Material (ESM)) (Slimani et al. 2000). GloboDiet is a software that is used for 24-h dietary recall surveys. For convenience, some GloboDiet groups were aggregated into one group. The food group 'vegetables' also included potatoes and legumes, 'dairy' included ice cream and butter as well, 'cereals' also included cakes and snacks, and alcoholic beverages, non-alcoholic beverages and soy drink were aggregated into the food group 'beverages'.

LCIA results were combined with data from the Dutch national food consumption survey 2007-2010 (Van Rossum et al. 2011) to calculate the average Dutch daily dietary environmental impact per person based on a selection of foods. The consumption survey is based on two 24-h recall interviews by telephone of 7-69-year-old men and women. Foods that were reported in the consumption survey but were missing in the LCIA results were omitted from further calculations, which leads to an underestimation of total dietary environmental impact.

\subsection{LCIA}

Calculations were done with SimaPro 8.3.0 software (Pre-sustainability 2018), and the characterisation methods used were ReCiPe 2008 V1.12 (Goedkoop et al. 2009) and ReCiPe 2016 V1.1 (Huijbregts et al. 2016). LCIA results were determined on midpoint and endpoint level with CFs for global averages for all three sets of $\mathrm{CFs}$ provided by $\mathrm{ReCiPe}$, i.e. following different value choices. The analysis on endpoint level 
focused on the areas of protection for human health and ecosystems, for which all available damage pathways were included. The LCI was considered incomplete for resource depletion but results are included in the supplementary information. The analysis on midpoint level mainly focussed on the six impact categories for which the LCI was originally composed: climate change, water use, land use, freshwater eutrophication, marine eutrophication and terrestrial acidification.

ReCiPe 2016 offers the possibility to perform LCIA with country-specific CFs for water use, acidification, freshwater eutrophication, fine particulate matter formation and ozone formation. Therefore, LCAs were also performed with Dutch CFs of ReCiPe 2016. This was done on midpoint and endpoint level for terrestrial acidification, freshwater eutrophication and particulate matter formation. For this, we adapted the ReCiPe 2016 method available in SimaPro to match the Dutch-specific CFs. Although the LCI does not include foreground data on direct particulate matter emissions, it does include secondary inorganics and could thus be included in the analysis with country-specific CFs. The regional impacts of water consumption were only examined on endpoint level for both global-average ReCiPe 2016 CFs and Dutch regional-specific CFs because the LCI consisted of water consumed and the CFs for water consumed on midpoint level are equal (both have a CF of 1). The same inventory was used for global as well as regional analysis. It should be noted that the food within the LCI originated from different regions, and all foods have various production steps that do not take place in the Netherlands while using Dutch CFs assumes all impacts take place in the Netherlands. Regional impact assessment with Dutch CFs was chosen since the LCI was composed of foods that were available on the Dutch market and the final life cycle stages take place in the Netherlands. The analysis was done to show the difference between using globalaverage CFs, provided as defaults in ReCiPe, and using country-specific CFs. Therefore, it does not necessarily provide a more accurate representation of the impact food consumption has in the Netherlands, as the LCI consists of life cycle stages that also occur outside the Netherlands.

\subsection{Interpretation}

Differences in LCIA results using ReCiPe 2008 and 2016 based on global CFs were assessed for all foods grouped together, for each food group and for individual foods within each food group. Results expressed as absolute values were compared with a two-sided $t$ test, the root mean square error (RMSE) and the normalised RMSE. Rankings were compared with the Spearman rank test. The RMSE is an indication of how well the data fit the 1:1 line (Timsina and Humphreys 2006; Lautz et al. 2017). Although the RMSE is originally a measure to compare predicted and observed values, it was considered as an appropriate test to compare LCIA results based on ReCiPe 2008 and ReCiPe 2016. The normalised RMSE value was calculated by dividing the RMSE by the average ReCiPe 2008 impact. Normalisation of the RMSE was required in order to compare the RMSEs of different impact categories. LCA results of all foods per impact category based on ReCiPe 2016 with global-average CFs and ReCiPe 2016 with Dutch regional-specific CFs were compared with a two-sided $t$ test, the RMSE and the normalised RMSE and a Spearman rank test. The average daily dietary environmental impact based on ReCiPe 2008 and ReCiPe 2016 was compared with a two-sided $t$ test. Significant differences assessed with the $t$ test were assumed at $p<0.05$. Statistical analysis was done with R-studio version 3.4.0. The RMSE was performed with the Metrics package (Core Team 2017a), the Spearman rank test and the $t$ test with the stats package (Core Team 2017b).

\section{Results}

\subsection{Endpoint level}

Figure 1 shows the environmental impact on endpoint level for each food item calculated with ReCiPe 2008 and ReCiPe 2016. ReCiPe 2008 and 2016 showed a strong correlation for each area of protection and each perspective, with no significant difference in ranking of foods (Spearman's rho $>0.76$ ). From an individualist perspective, the impact on human health was estimated to be significantly smaller when using ReCiPe 2016 ( $p<0.001$ on average). From an egalitarian perspective, the product-specific impact of foods on human health was estimated to be significantly larger when using ReCiPe 2016 $\left(p<0.001\right.$ with $\left.\mathrm{RMSE}=0.0001, \mathrm{RMSE}_{\text {norm }}=329.2\right)$. There was no significant difference between ReCiPe 2008 and 2016 for damage to human health from an hierarchist perspective $(p=0.39)$ and there were relatively small differences in predicted impacts $\left(\mathrm{RMSE}=0.00, \mathrm{RMSE}_{\text {norm }}=39.4\right)$. Damage to ecosystems was estimated to be significantly smaller in ReCiPe 2016 form an individualist, hierarchist and egalitarian perspective $(p<0.05)$. Predicted endpoint effects on resource depletion were significantly larger for all foods in ReCiPe 2016 ( $t$ test, $p<0.05$, ESM, Fig. S3). Foods were predicted to cause more damage to resource depletion with $\mathrm{ReCiPe}$ 2016 from an individualist perspective $\left(\mathrm{RMSE}_{\text {norm }}=8.3\right)$. Ranking between food categories was similar in ReCiPe 2016 to the ranking in ReCiPe 2008, Spearman's rho was around 0.95 for each combination of area of protection and perspective. Within food categories, there were no significant differences in ranking except for the ranking of the impact on human health of fruit products from an individualist perspective $(p>0.05)$ (ESM, Fig. S4).

Figure 2 shows the endpoint damage on human health and ecosystems per midpoint category for foods using ReCiPe 
I

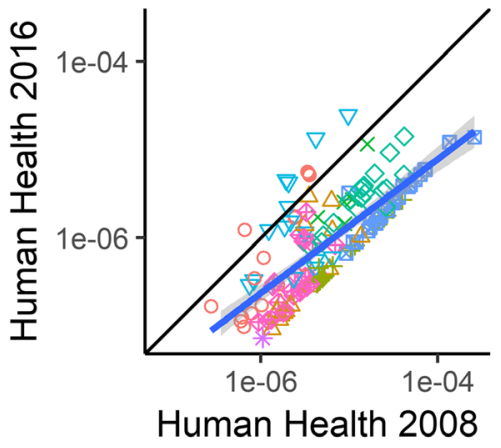

I

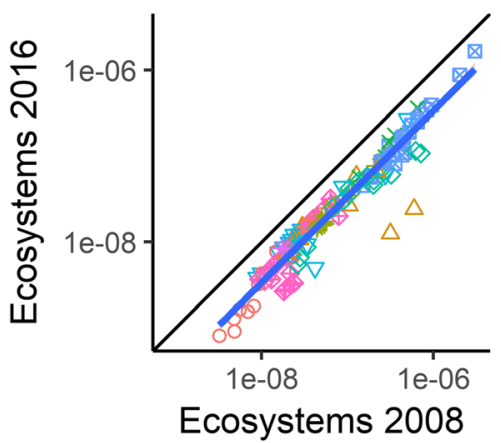

$\mathrm{H}$

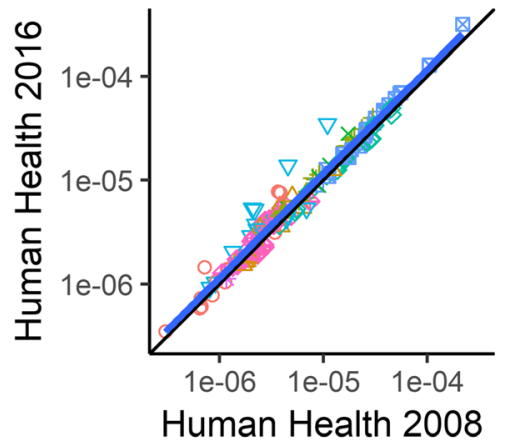

$\mathrm{H}$

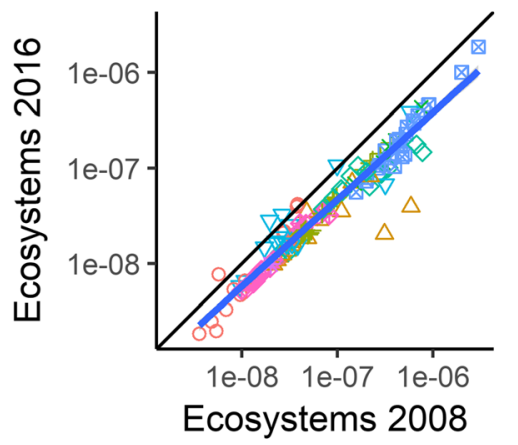

$\mathrm{E}$

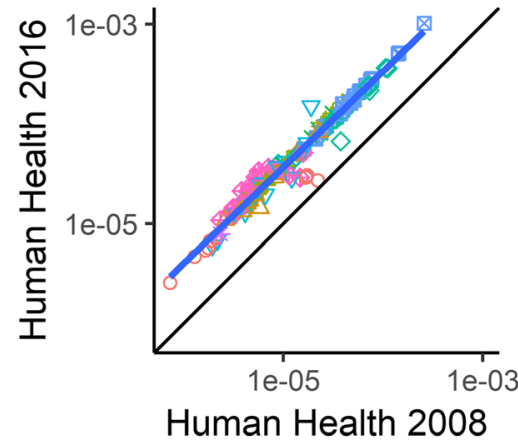

$\mathrm{E}$

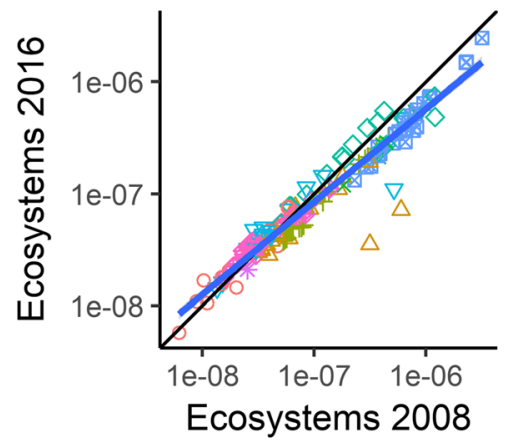

\section{Category \\ - Beverages + Dairy $\diamond$ Fish $\otimes$ Meat \\ Cereals $\times$ Fat}

Fig. 1 Impact per kilogramme of food for 152 foods using ReCiPe 2016 versus ReCiPe 2008. Impacts for two areas of protection (human health and ecosystems) and for three different perspectives (individualist (I), hierarchist $(\mathrm{H})$ and egalitarian $(\mathrm{E})$. Line for best fit in blue, black line indicates the 1:1 line
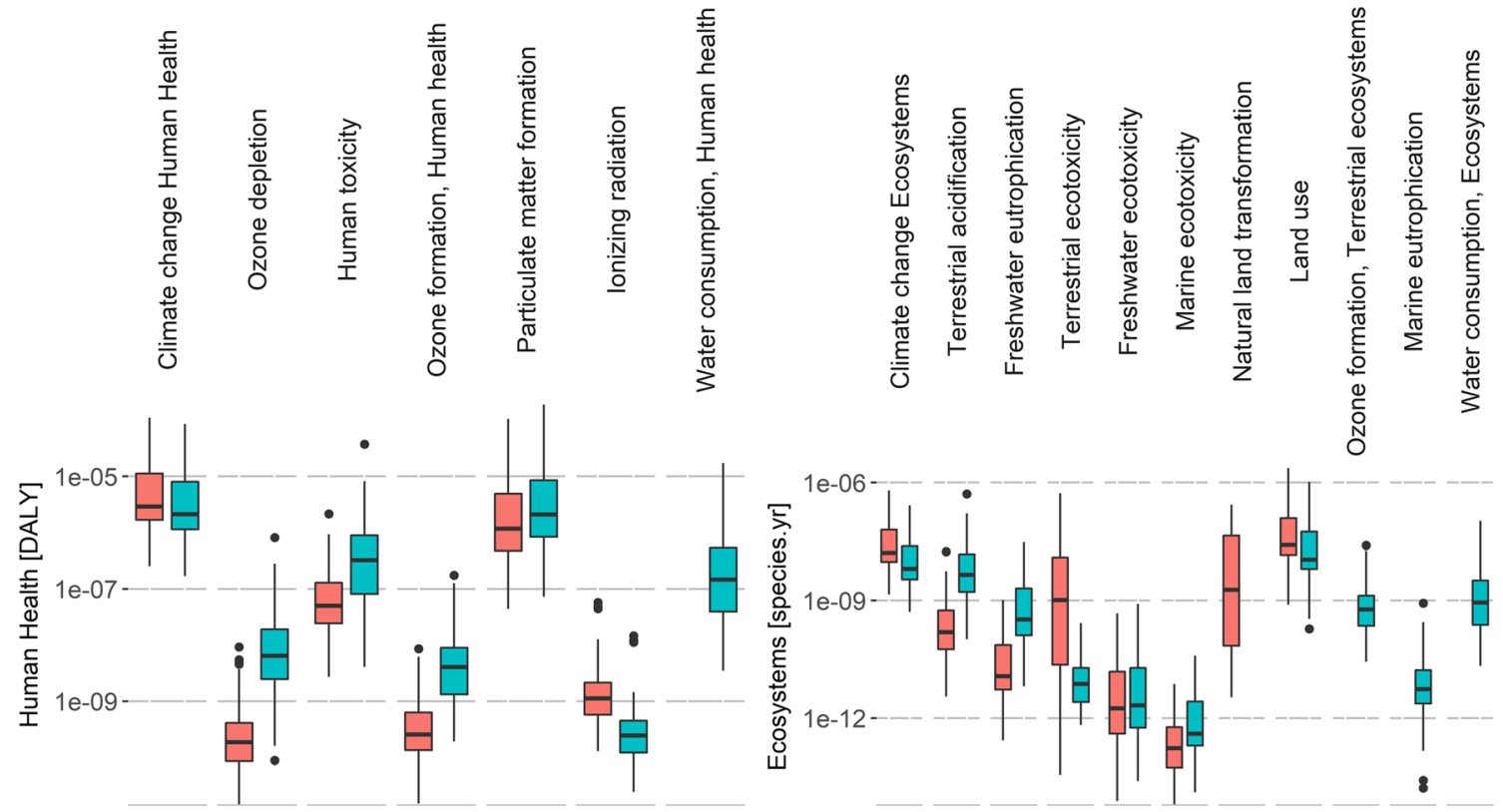

Version 官 2008 官 2016

Fig. 2 Boxplots of endpoint damage of foods $(n=152)$ per midpoint impact category in ReCiPe 2008 and ReCiPe 2016 from an hierarchist perspective. Bars show median values, lower and upper hinges correspond to the 25th percentiles and 75 th percentiles and whiskers extend to 1.5 inter-quartile distance 
2008 and 2016 for the hierarchist perspective. Damage to human health from foods was in large part caused by climate change and fine particulate matter formation, both in ReCiPe 2008 and in ReCiPe 2016 (Fig. 2 and ESM, Figs. S6-S8). From a hierarchist perspective, damage to human health from climate change was on average a factor 0.7 lower in $\mathrm{ReCiPe}$ 2016. Particulate matter impacts were on average a factor 1.8 higher in ReCiPe 2016. Predicted damage from human toxicity was a factor of 10.3 larger with ReCiPe 2016, to account on average for $10 \%$ of the total damage to human health. No endpoint CFs were available for water consumption in ReCiPe 2008, but for predicted impacts with ReCiPe 2016, water consumption accounted on average for $7 \%$ for damage to human health. Ozone depletion, ionising radiation and ozone formation contributed less than $1 \%$ to the total damage to human health with both versions of ReCiPe. Ozone depletion was predicted to cause 55 times more damage to human health with ReCiPe 2016 compared to ReCiPe 2008. Ozone formation was predicted to cause 15 times more damage to human health.

Damage to ecosystems from foods was mostly caused by climate change, land use and land transformation, both in ReCiPe 2008 as in ReCiPe 2016 (Fig. 2 and Fig. S9-S11 (ESM)). From a hierarchist perspective, damage to ecosystems from climate change was on average a factor 0.4 lower predicted by ReCiPe 2016 compared to ReCiPe 2008. Land use damage was predicted to be half of the damage with $\mathrm{ReCiPe} 2016$ than it was when predicted with $\mathrm{ReCiPe}$ 2008. On the other hand, the predicted effect of terrestrial acidification was on average a factor 22.2 larger with ReCiPe 2016. With ReCiPe 2016, an effect on ecosystems through acidification was predicted of $14 \%$ of the total damage to ecosystems, while with $\mathrm{ReCiPe} 2008$, a minimally contributing effect $(<0.5 \%)$ was predicted. On average, ecotoxicity made up around $4 \%$ of the total damage to ecosystems when ReCiPe 2008 was applied, while with ReCiPe 2016, any effects were hardly predicted $(<0.1 \%)$ on ecosystems through ecotoxicity. Endpoint effects on ecosystems due to water consumption were not included in $\mathrm{ReCiPe} 2008$. Applying $\mathrm{ReCiPe} 2016$, water consumption accounted on average for $5 \%$ of the damage to ecosystems. Within the food categories fruit and beverages, however, water use had a relatively larger impact, accounting on average for $16 \%$ and $11 \%$ of the total damage to ecosystems for each perspective. Ozone formation effects on ecosystems were not included in ReCiPe 2008. ReCiPe 2016 estimated on average a small contribution of ozone formation to the total damage to ecosystems $(<0.6 \%)$. Ozone formation contributed more to ecosystem damage for fish products than other foods, i.e. on average $10 \%$ of the total endpoint damage. This damage was mostly caused by the burning of diesel fuels through the various life cycle stages of the fish products.

\subsection{Midpoint level: individual products}

Figure 3 shows the environmental impacts of foods from a hierarchist perspective for the midpoint categories for which the LCI was considered complete (for other perspectives, see supplementary data, Fig. S12 (ESM)). On midpoint level, the calculated impact of foods remained similar when using $\mathrm{ReCiPe} 2016$ compared to ReCiPe 2008. The ranking of foods did not change significantly (Spearman's rho $=0.99$ ). There was no significant difference between results based on ReCiPe 2008 and ReCiPe 2016 for climate change, acidification, water use and land use for all perspectives $(p>0.05)$. For these midpoint categories, the RMSE ${ }_{\text {norm }}$ was below 1, indicating that the difference between ReCiPe 2008 and ReCiPe 2016 values was smaller than the average value from $\mathrm{ReCiPe}$ 2008. There was a significant difference between ReCiPe 2008 and ReCiPe 2016 for freshwater eutrophication $(p=$ 0.02 ) for the three different perspectives with an $\mathrm{RMSE}_{\text {norm }}$ of 2.1 for the three different value choices. Marine eutrophication was predicted to be significantly lower with ReCiPe 2016 for each value choice $(p<0.01)$.

\subsection{Regionalisation}

Differences were observed between LCA results with ReCiPe 2016 global-average CFs and ReCiPe 2016 Dutch-specific CFs (Fig. S13 (ESM)). On midpoint level, terrestrial acidification was predicted to be significantly larger with Dutchspecific CFs $(p<0.05)$. Freshwater eutrophication was predicted to be significantly smaller with Dutch-specific CFs on midpoint level and endpoint level $(p<0.001)$. Normalised RMSE was below 1 for fine particulate matter formation on mid- and endpoint level, as well as for terrestrial acidification on endpoint level. There was no difference in ranking of foods between ReCiPe 2016 using global-average or Dutch CFs for terrestrial acidification, particulate matter formation or freshwater eutrophication.

ReCiPe 2016 includes endpoint CFs for damage to human health and ecosystems due to water consumption. The Dutch endpoint $\mathrm{CF}$ for water consumption on aquatic ecosystems was 0 (compared to the global-average CF of $6.04 \cdot 10^{-13}$ species year $\left./ \mathrm{m}^{3}\right)$. Impact of water consumption on human health was lower with Dutch CF (Fig. 4; $(p<0.001)$. There was a significant difference between the use of global-average and Dutch CFs on the effect of water consumption on terrestrial ecosystems $(p<0.01)$. Normalised RMSE showed a large difference between global-average and regionalised $\mathrm{CFs}$ with normalised RMSE of 3.5 for damage to human health and 12.2 for damage to terrestrial ecosystems. Spearman's rank showed no significant differences between the results with global-average CFs compared to the results with the Dutch CFs (Spearman's rho $=1$ ). 

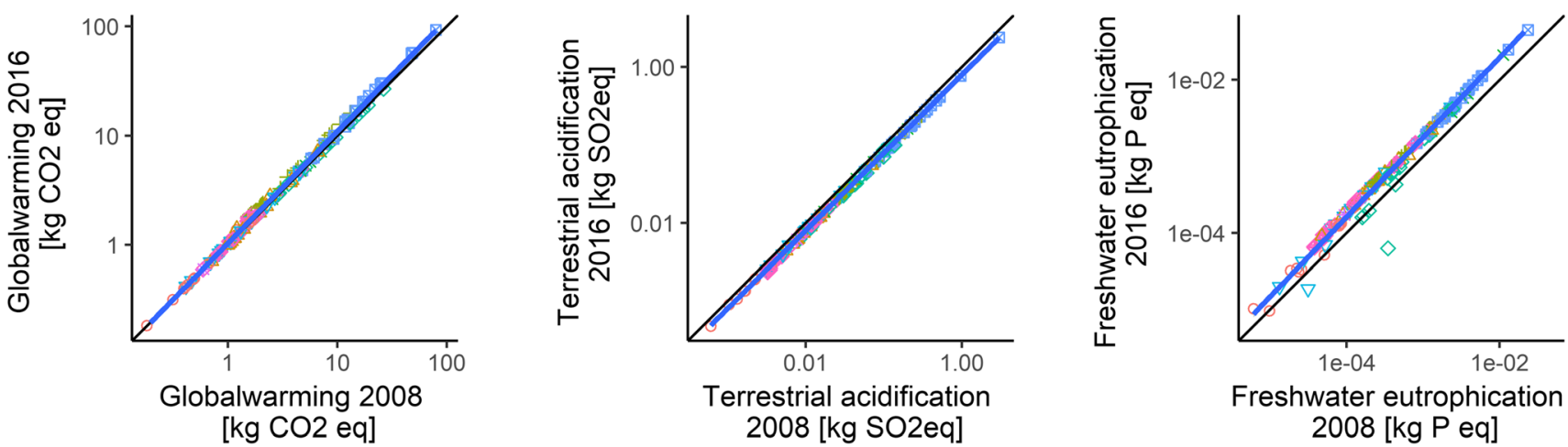

Freshwater eutrophication 2008 [kg P eq]
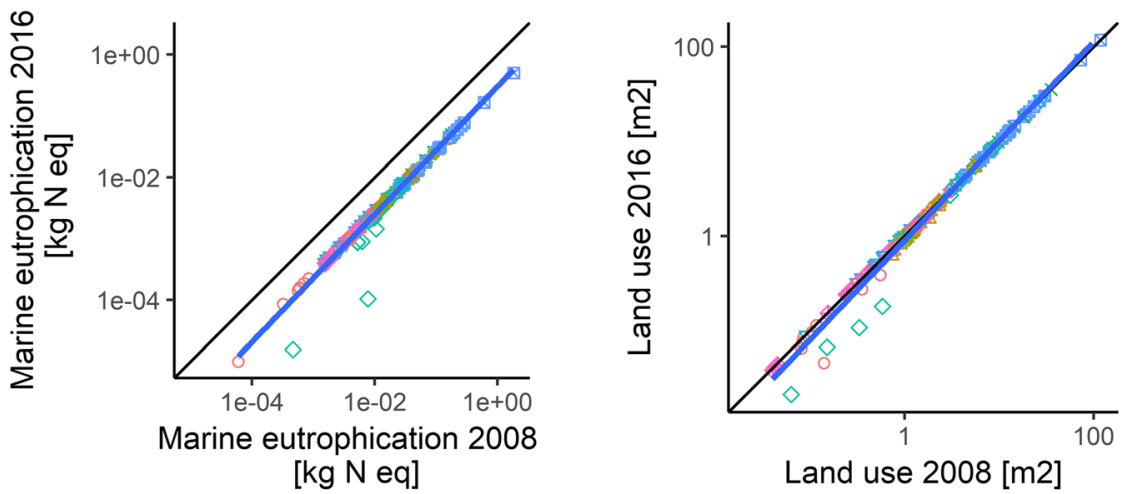

Category

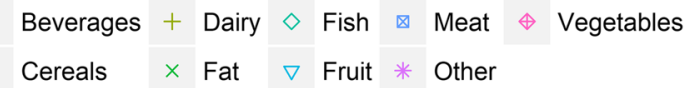

Fig. 3 Impact per kilogramme of food for 152 foods in ReCiPe 2016 compared with ReCiPe 2008. Impacts for six midpoint categories (global warming, freshwater eutrophication, terrestrial acidification,

water use, and land use) from a hierarchist perspective. Line for best fit in blue, black line indicates 1:1 line

acidification was predicted to be significantly lower with ReCiPe $2016(p<0.05)$ for each food category. Freshwater eutrophication was predicted to be significantly larger for each food category $(p<0.05)$ with ReCiPe 2016, while marine eutrophication was predicted to be significantly smaller for each food category $(p<0.05)$. Beverages, dairy and fish were predicted to require significantly less land $(p<0.01)$.
Fig. 4 Endpoint damage for water consumption per kilogramme of 152 foods in ReCiPe 2016, with globalaverage ( $x$-axis) and Dutchspecific CFs ( $y$-axis) from a hierarchist perspective. Line for best fit in blue, black lines indicate the $1: 1$ line

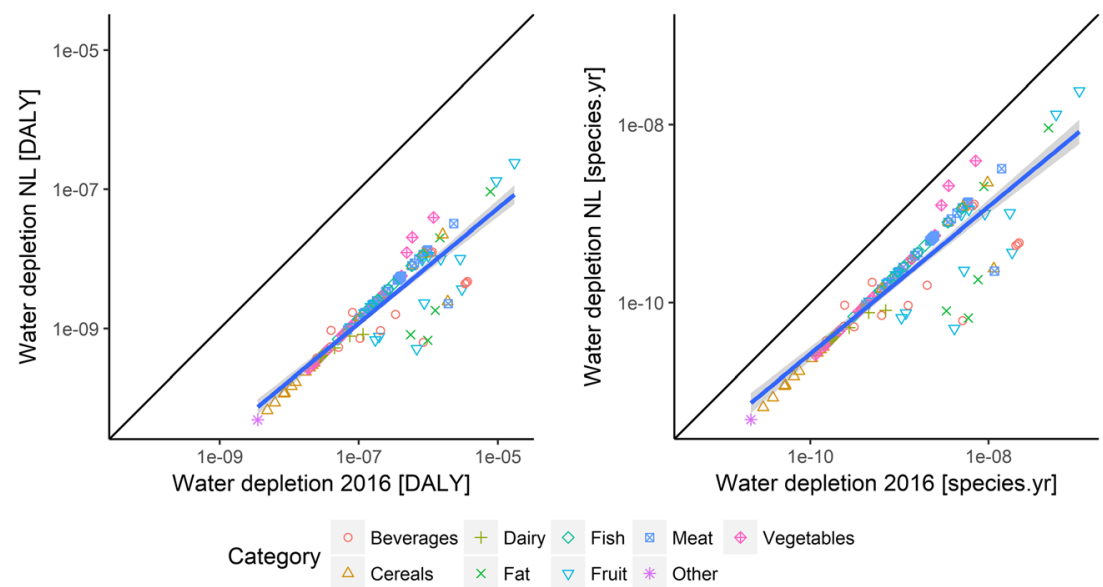



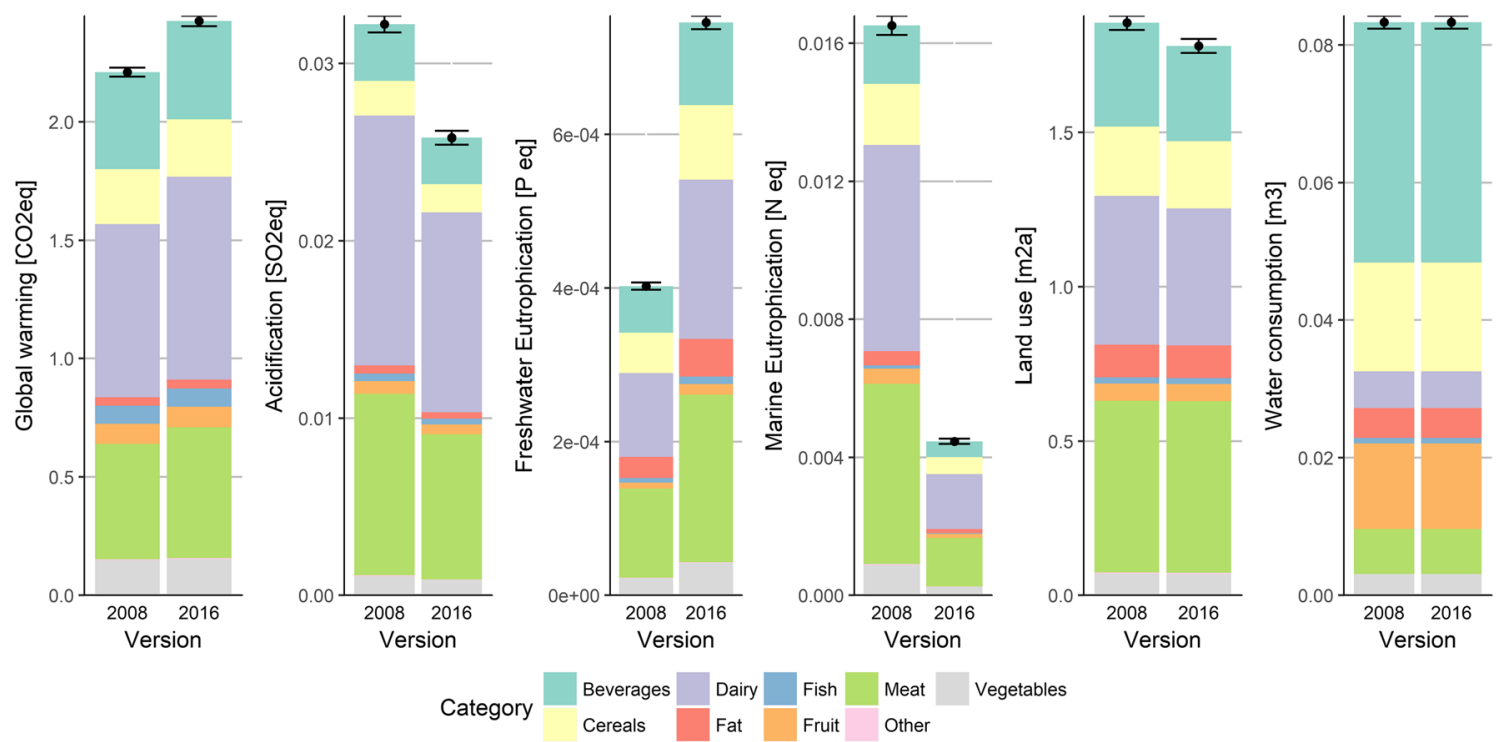

Fig. 5 Midpoint effects of the average daily impact for consumption of the 152 foods included in this study, determined with ReCiPe 2008 and ReCiPe 2016 for persons aged 7-69. Bars indicate the standard error. All impacts are from an hierarchist perspective

\section{Discussion}

\subsection{Explanation of the findings}

Results from LCAs of food products, performed with ReCiPe 2008 and 2016, showed a large correlation. However, small differences in ranking remained. The differences in ranking between ReCiPe 2008 and 2016, of individual foods contributing to damage to human health, is mostly caused by a difference in a change in incorporated substances and new damage pathways. In ReCiPe 2016, the damage through particulate matter formation differs stronger between the three value choices, with different incorporated substances (e.g. $\mathrm{PM}_{2.5}$ versus $\mathrm{PM}_{10}$ ), which causes a change in ranking for damage to human health from an egalitarian and hierarchist perspective. The addition of water consumption in damage to human health in ReCiPe 2016 was another factor that influenced the ranking of foods, but it is seldom the only reason changes in ranking occur. For example, beef is a product that uses a lot of water in the production process. In the hierarchist perspective, ReCiPe 2016 predicted $23 \%$ more damage to human health. Ten percent of this rise of damage to human health was however caused by the addition of water consumption in ReCiPe 2016 (ESM, Fig. S7). There are also some product groups where changes between ReCiPe 2008 and 2016 are mostly caused by the addition of water consumption. Within the product group fruits, this effect is most visible. That is $70 \%$ of the difference in damage to human health between ReCiPe 2008 and ReCiPe 2016 was caused by the additional impacts of water consumption (ESM-Fig. S7bb). Also, differences in ranking in damage to ecosystems were mostly caused by the inclusion of a damaged pathway for water consumption (i.e. within the product group fruits) in ReCiPe 2016 and furthermore in differences in ecotoxicity effects between $\mathrm{ReCiPe}$ 2008 and 2016.

Differences in absolute results between ReCiPe 2008 and 2016 on endpoint level were largest for the area of protection human health. For the egalitarian perspective, the differences in results between ReCiPe 2008 and 2016 can be explained by a change in the time horizon for the egalitarian perspective from 500 to 1000 years (or infinite) for climate change and acidification (Huijbregts et al. 2016). Differences in absolute values from an individualist perspective are in part caused by a lower mid to endpoint CF for climate change in ReCiPe 2016, $8.1 \cdot 10^{-8} \mathrm{DALY} / \mathrm{kgCO}_{2}$-eq compared to $1.19 \cdot 10^{-6} \mathrm{DALY} / \mathrm{kg}$ $\mathrm{CO}_{2}$-eq in $\mathrm{ReCiPe} 2008$.

Furthermore, in ReCiPe 2016, only $\mathrm{PM}_{2.5}$ is incorporated to contribute to particulate matter formation, while in $\mathrm{ReCiPe}$ 2008, $\mathrm{PM}_{10}$ was incorporated. This is because research showed that most life years lost can be attributed to smaller particles. Also, there is a difference in incorporated substances for the different value choices in ReCiPe 2016. While the individualist perspective only incorporates effects of direct emission of $\mathrm{PM}_{2.5}$, the hierarchist and the egalitarian perspective incorporates effects of secondary particles ammonia, sulphur oxides and nitrogen oxides as well. In ReCiPe 2008, this difference between value choices is absent. Although the LCI did not specifically include substances causing stratospheric ozone depletion or photochemical ozone formation, there was a large difference in predicted damage through these pathways. This difference in damage to human health through ozone depletion was mostly caused by the inclusion of a $\mathrm{CF}$ for dinitrogen mono-oxide in ReCiPe 2016, which is lacking in $\mathrm{ReCiPe} 2008$. The larger contribution to human health 
damage of ozone formation was caused by updated CF's that are applicable to a global scale and the inclusion of chronic mortality instead of acute mortality.

With ReCiPe 2008, some dairy and meat products were predicted to cause larger endpoint level impacts for climate change from an Individualist perspective than from a Hierarchist perspective. While the global-average mid- to endpoint $\mathrm{CF}$ for climate change is larger from a hierarchist perspective than the individualist perspective. This is due to the large mid- to endpoint $\mathrm{CF}$ for methane for the individualist perspective in the 2008 version. In ReCiPe 2016, the mid- to endpoint damage pathway is now included in a more clear and scientifically consistent way, leading to larger factors for the hierarchist perspective than for the individualistic perspective.

Predicted impacts on climate change of the Dutch diet were lower than expected compared to previous studies of the Dutch diet and compared to other countries (Fig. S5 (ESM)) (Temme et al. 2014; De Valk et al. 2016; Goldstein et al. 2016). This was mainly caused by the limited number of foods within this study and the inclusion of children, where other studies focus on adults only. In addition, underreporting of daily food intake by consumers might be another reason (Berners-lee et al. 2012).

\subsection{Uncertainty}

This work included many and large datasets, making it vulnerable to various sources of uncertainty.

First, it was not possible to thoroughly compare the differences between ReCiPe 2008 and ReCiPe 2016 for ozone depletion, pesticide toxicity, ozone formation caused by individual non-methane volatile organic compounds and ionising radiation. This was caused by gaps in the LCI database.

Identifying all emissions of toxic compounds was not in the scope of the LCI thus, the LCI does not contain data on pesticide use. This caused a severe underestimation of the true contribution to human and ecotoxicity of food consumption. Toxicity effects were only predicted for exposure to heavy metals mostly emitted during the cultivation and packaging stages of the foods. However, toxicity still has a large effect on the total damage to human health and ecosystems in this study. Differences in toxicity effects between ReCiPe 2008 and ReCiPe 2016 can partly be explained by differences in midto endpoint factors. Some of the analysed foods (i.e. cashew nuts and wine) have large emissions of zinc in the cultivation stages of their life cycle (Benedetto 2013; Figueiredo et al. 2014). The endpoint CF for zinc differs a factor of 300 between ReCiPe 2008 and 2016 from an egalitarian perspective. Zinc is just one of the substances for which the CFs changed far more than the average mid- to endpoint factor for toxicity. In this case study, however, none of these other substances were found to alter the impact between ReCiPe 2008 and 2016 as much as zinc did.
Second, it was not possible for this study to apply regionalised $\mathrm{CFs}$ based on the place of production. Instead, regionalised CFs were applied as if all foods included in this study had been produced in the Netherlands. Preceding LCA studies that compared different production sites often only compared the emissions but did not take into account the regional differences in sensitivity to these emissions (Page et al. 2014; Steenwerth et al. 2015). When comparing two distinct production sites, this should, however, be taken into consideration. Our results showed that regional-specific analysis might change the ranking of foods, as impacts with Dutch regionalspecific CFs differed significantly from impacts with globalaverage CFs. Differences between global-average and regional-specific results may be smaller or larger when choosing another country with more or less distinct CFs (Huijbregts et al. 2016). For a globalised production chain, there is currently a methodological challenge in how to calculate the regionalspecific impacts. Whenever regionalisation is possible, it offers a more in-depth look at how foods affect the environment (Mutel and Hellweg 2008). In this study, an oversimplification was done as it was not possible to perform a regionalised LCIA for food that has production steps in different regions. For this to be possible, an LCI with more details about the place of production is needed. Furthermore, there is a need for an option within LCA software to use region-specific CFs for different life cycle stages (Mutel and Hellweg 2008). Following a recent discussion forum on regionalisation, software developers aim to focus on ways to implement spatially explicit LCI data and characterisation factors in LCI databases and LCA software (Frischknecht et al. 2019).

\section{Conclusions and recommendations}

The use of ReCiPe 2016 leads to different results compared to the use of ReCiPe 2008 in absolute values. This was expected because ReCiPe 2016 contains new and updated damage pathways, which led to other CFs. On the other hand, the relative results, the ranking, the between and within food categories did not change to a large extent. This means that in most studies on food items that used ReCiPe 2008, the interpretation of the results is not likely to change when applying ReCiPe 2016 instead of the 2008 version with the same inventory. This is especially the case when the mostly used hierarchical perspective is being applied or when performing a midpoint level analysis. Endpoint level LCAs conducted with ReCiPe 2008 should be updated, especially for products that emit large amounts of $\mathrm{PM}_{2.5}$ or its precursors or consume large amounts of water throughout their life cycle. Also, the findings of this study indicate that studies with ReCiPe 2008 on products that have large emissions of toxin compounds should be re-evaluated with ReCiPe 2016, as predicted impacts will be larger. 
Regional assessment with Dutch CFs resulted in significant differences in absolute values, but not directly to other rankings. Since regional matters affect the CFs, the application of regional impact assessment within LCA requires more attention. A particular region might be more susceptible to a certain impact than others, indicating the necessity to mitigate impacts of certain emissions or resource used. However, this also gives rise to other potential concerns, partly led by market and production processes changes, as also outlined by Bueno et al. (2016). Region-specific CFs are now available and often LCIs as well, but the LCA software is not yet sufficiently developed for consequent implementation of these CFs. Software developers are working on this (Frischknecht et al. 2019) and some case study work has been done with regional-specific CFs (Brightway 2018), where possible region-specific CFs should be used.

Updates of LCIA methods are necessary to reflect the scientific state of the art, but can have consequences for studies that use the method. It is therefore recommended to include insights on practical consequences of old studies when updates are released, that is, insight in what type of studies might show different results due to the update.

Furthermore, the results of this study underpin the importance of careful interpretation of LCA results. LCA results can always be used in comparison (trends, hotspots, choices on products), but the comparison of LCA results with absolute boundaries or goals should be approached with care (Wulf et al. 2018). Further development of the LCIA method remains important, as new insights could lead to inclusions of impacts that were completely neglected before, causing a shift in future rankings, and a more robust LCA method leads to less uncertainty in the LCA results.

Acknowledgements Special thanks are given to Jasper Scholten from Blonk Consultants for the help with the LCI and Katarzyna Cenian from PRé Consultants for the help with the implementation of ReCiPe 2016 v1.1 into SimaPro. Thanks are given to Elias de Valk and Anne Hollander for reviewing an earlier version of this article.

Open Access This article is distributed under the terms of the Creative Commons Attribution 4.0 International License (http:// creativecommons.org/licenses/by/4.0/), which permits unrestricted use, distribution, and reproduction in any medium, provided you give appropriate credit to the original author(s) and the source, provide a link to the Creative Commons license, and indicate if changes were made.

\section{References}

Benedetto G (2013) The environmental impact of a Sardinian wine by partial life cycle assessment. Wine Econ Policy 2:33-41. https://doi. org/10.1016/j.wep.2013.05.003

Berners-lee M, Hoolohan C, Cammack H, Hewitt CN (2012) The relative greenhouse gas impacts of realistic dietary choices. Energy Policy 43:184-190. https://doi.org/10.1016/j.enpol.2011.12.054
Blonk Agri-footprint BV. (2015) Agri-footprint - part 1 - methodology and basic principles. Gouda, The Netherlands

Brightway (2018) Brightway2 LCA framework. https://brightwaylca.org/. Accessed 20 Aug 2018

Broekema R, Kuling L, Scholten J (2015a) Life cycle inventories of dairy- and animal products consumed in the Netherlands

Broekema R, Kuling L, Scholten J (2015b) Life cycle inventories of fish products consumed in the Netherlands

Broekema R, Kuling L, Koukouna E (2016) Life cycle inventories of nuts, potatoes and beverages consumed in the Netherlands also includes some types of vegetables breads and fish

BSI (2012) PAS 2050-1:2012. Assessment of life cycle greenhouse gas emissions from horticultural products

Bueno C, Hauschild MZ, Rossignolo JA, Ometto AR, Mendes NC (2016) Sensitivity analysis of the use of life cycle impact assessment methods: a case study on building materials. J Clean Prod 112: 2208-2220. https://doi.org/10.1016/j.jclepro.2015.10.006

Cavalett O, Ferreira Chagas M, Seabra JEA, Bonomi A (2013) Comparative LCA of ethanol versus gasoline in Brazil using different LCIA methods. Int J Life Cycle Assess 18:647-658. https://doi. org/10.1007/s11367-012-0465-0

Core Team R (2017a) Package "Metrics"

Core Team R (2017b) Package "Stats"

De Valk E, Hollander A, Zijp M (2016) Milieubelasting van de voedselconsumptie in Nederland. Bilthoven, The Netherlands

Figueiredo M, Potting J, Serrano L, Bezerra MA, Barros V. da S., Gondim RS, Nemecek T (2014) Life cycle assessment of Brazilian cashew. In: Proceedings of the 9th International Conference on Life Cycle Assessment in the Agri-Food Sector. San Francisco, USA

Finkbeiner M, Inaba A, Tan RBH, Christiansen K, Klüppel HJ (2006) Commentaries the new international standards for life cycle assessment: ISO 14040 and ISO 14044. Int J Life Cycle Assess 11:80-85. https://doi.org/10.1065/lca2006.02.002

Frischknecht R, Pfister S, Bunsen J, Haas A, Känzig J, Kilga M, Lansche J, Margni M, Mutel C, Reinhard J, Stolz P, van Zelm R, Vieira M, Wernet $\mathrm{G}$ (2019) Regionalization in LCA: current status in concepts, software and databases - 69th LCA forum, Swiss Federal Institute of Technology. Int J Life Cycle Assess 24:364-369. https://doi.org/ 10.1007/s11367-018-1559-0

Goedkoop M, Heijungs R, Huijbregts M, De Schryver A, Struijs J, Van Zelm R.. 2009 ReCiPe 2008. A life cycle impact assessment method which comprises harmonised category indicators at the midpoint and the endpoint level. Ministry of Housing, Spatial Planning and the Environment, The Netherlands. First edition. Report I: Characterisation

Goldstein B, Foss S, Gjerris M, Laurent A, Birkved M (2016) Ethical aspects of life cycle assessments of diets. Food Policy 59:139-151. https://doi.org/10.1016/j.foodpol.2016.01.006

Hauschild MZ, Goedkoop M, Guinée J, Heijungs R, Huijbregts M, Jolliet O, Margni M, de Schryver A, Humbert S, Laurent A, Sala S, Pant R (2013) Identifying best existing practice for characterization modeling in life cycle impact assessment. Int J Life Cycle Assess 18:683697. https://doi.org/10.1007/s11367-012-0489-5

Huijbregts MAJ, Steinmann ZJN, Elshout PMF, Stam G, Verones F, Vieira M, Zijp M, Hollander A, van Zelm R (2016) ReCiPe2016. A harmonized life cycle impact assessment method at midpoint and endpoint level. Report I: Characterization. RIVM Report 20160104. National Institute for Human Health and the Environment, Bilthoven.

JRC (2015) Baseline approaches for the cross-cutting issues of the cattle related product environmental footprint pilots in the context of the pilot phase

Koiwanit J, Piewkhaow L, Zhou Q et al (2014) A life cycle assessment study of a Canadian post-combustion carbon dioxide capture process system. 19:357-369. https://doi.org/10.1007/s11367-013-0649-2 
Kuling L, Scholten J (2015) Life cycle inventories of vegetables consumed in the Netherlands. Guidance document. Blonk Consultants. Gouda, the Netherlands:

Kuling L, Valencia-Martinez E, Scholten J (2015) Life cycle inventories of fruit consumed in the Netherlands

Lautz LS, Struijs J, Nolte TM, Breure AM, van der Grinten E, van de Meent D, van Zelm R (2017) Chemosphere evaluation of SimpleTreat 4.0: simulations of pharmaceutical removal in wastewater treatment plant facilities. Chemosphere 168:870-876. https:// doi.org/10.1016/j.chemosphere.2016.10.123

Manfredi M, Vignali G (2014) Life cycle assessment of a packaged tomato puree: a comparison of environmental impacts produced by different life cycle phases. J Clean Prod 73:275-284. https://doi.org/ 10.1016/j.jclepro.2013.10.010

Mutel CL, Hellweg S (2008) Regionalized life cycle assessment: methodology and application to inventory databases. Environ Sci Technol 43:5797-5803. https://doi.org/10.1021/es803002j

Page G, Ridoutt B, Bellotti B (2014) Location and technology options to reduce environmental impacts from agriculture. J Clean Prod 81: 130-136. https://doi.org/10.1016/j.jclepro.2014.06.055

Pre-sustainability (2018) SimaPro

Slimani N, Ferrari P, Ocke M, Welch A, Boeing H, van Liere M, Pala V, Amiano P, Lagiou A, Mattisson I, Stripp C, Engeset D, Charrondière R, Buzzard M, van Staveren W, Riboli E (2000) Standardization of the 24-hour diet recall calibration method used in the European Prospective Investigation into Cancer and Nutrition (EPIC): general concepts and preliminary results. Eur J Clin Nutr 54:900-917. https://doi.org/10.1038/sj.ejcn.1601107

Smetana S, Mathys A, Knoch A, Heinz V (2015) Meat alternatives: life cycle assessment of most known meat substitutes. Int J Life Cycle Assess 2050:1254-1267. https://doi.org/10.1007/s11367-015-0931-6
Steenwerth KL, Strong EB, Greenhut RF, Williams L, Kendall A (2015) Life cycle greenhouse gas, energy, and water assessment of wine grape production in California. Int J Life Cycle Assess 20:12431253. https://doi.org/10.1007/s11367-015-0935-2

Temme EHM, Toxopeus IB, Kramer GFH, Brosens MCC, Drijvers JMM, Tyszler M, Ocké MC (2014) Greenhouse gas emission of diets in the Netherlands and associations with food, energy and macronutrient intakes. Public Health Nutr 18:2433-2445. https:// doi.org/10.1017/S1368980014002821

Timsina J, Humphreys E (2006) Performance of CERES-Rice and CERES-Wheat models in rice - wheat systems: a review. Agric Syst 90:5-31. https://doi.org/10.1016/j.agsy.2005.11.007

Van Rossum CTM, Fransen HP, Verkaik-Kloosterman J et al (2011) Dutch National Food Consumption Survey 2007-2010

Weidema BP, Bauer C, Hischier R, Mutel C, Nemecek T, Reinhard J, Vadenbo CO, Wernet G (2013) Data quality guideline for the ecoinvent database version 3. Ecoinvent Report 1(v3). St. Gallen: The ecoinvent Centre.

Wulf C, Werker J, Zapp P, Schreiber A, Schlör H, Kuckshinrichs W (2018) Sustainable development goals as a guideline for indicator selection in life cycle sustainability assessment. Procedia CIRP 69: 59-65. https://doi.org/10.1016/j.procir.2017.11.144

Publisher's note Springer Nature remains neutral with regard to jurisdictional claims in published maps and institutional affiliations. 